\title{
Eating Characteristics of Wieners Produced with Gari
}

\author{
Akwetey WY* and CL Knipe \\ Department of Animal Science, College of Agriculture and Natural Resources, Ghana
}

*Corresponding author: Akwetey WY, Department of Animal Science, College of Agriculture and Natural Resources, Kwame Nkrumah University of Science and Technology, Kumasi, Ghana.

\author{
Received Date: April 24, 2019
}

Published Date: May 23, 2019

\begin{abstract}
Texture and sensory profiles of wieners produced with either $0 \%$ or $3 \%$ gari, with $20 \%, 25 \%$ and $30 \%$ water respectively were studied. Using gari did not significantly $(p>0.05)$ influence cooking yield, odour and flavour in wieners. Consumer acceptability of texture attributes of wieners were significantly higher $(\mathrm{p}<0.05)$ in gari-treated wieners compared to the control because instrumental analysis of texture showed significant reductions $(\mathrm{p}<0.05)$ in hardness, springiness, gumminess, chewiness and cohesiveness when higher levels of water were incorporated. Adhesiveness was not influenced significantly $(\mathrm{p}>0.05)$ by treatment. The cost of producing wieners reduced by $8 \%, 35 \%$ and $41 \%$ respectively at $3 \%$ gari with $20 \%, 25 \%$ and $30 \%$ levels of using water. It was concluded that wieners could be manufactured with $3 \%$ gari and $25 \%$ water in order to save $41 \%$ of production costs and obtain desirable eating characteristics.
\end{abstract}

Keywords: Wieners; Gari; Texture and sensory profile; Consumer acceptability

\section{Introduction}

Food texture and sensory characteristics are very important aspects of consumer acceptability and several instrumental testing methods have been developed for texture profile analysis (TPA) of various foods [1,2]. These tests depend on measurements of resistance of a food sample to force deformation such as puncture, cutting, shear and tensile strength. According to [1] TPA's have the advantage of simplicity and the textural parameters obtained can be correlated with food texture sensory analysis. In recent times the most commonly used instrumental method is probably the compression method of texture profile analysis of foods because [3] had earlier suggested that this method mimicked the conditions to which food was subjected throughout a mastication process. Hence the compression parameters obtained with TPA have been employed by many researchers in their evaluations of meat products, including beef burgers and sausages, as a reliable scientific tool for determining the quality of a finished product and also, to select the best functional ingredients in order to optimize available resource inputs in the meat industry [4-8]. For example an instrumental measure of hardness as a component of the texture profile, offers information about the peak force at the first bite of a food product during mastication. So that ingredients which may offer some reduction in hardness and overall consumer acceptability could be beneficial in the search for softer and more 'tender-bite' processed meats such as wieners. Sensory evaluation was defined as a scientific principle used to evoke, measure, analyze and interpret those reactions to characteristics of food materials as perceived through the senses of sight, smell, taste, touch and hearing [9]. Human subjects are used as "instruments of measure" in the assessment of the complex sensations that result from the interactions of various food attributes and human senses in order to evaluate food quality in programmes such as quality control and new product development. When data generated from such sensory testing panels are statistically analyzed, the results may serve as an assay for the evaluation of, for example, the extent of flavor and odor desirability, especially when a new ingredient is being introduced into product manufacture for the first time. The sensory evaluation normally may be done by either a small number of people or by several hundreds of people depending on the types of information required. According to [10] most sensory characteristics of food can be seen to be measured well, meaningfully and completely only by human subjects. In using humans as instruments of measure, it is important to control all testing procedures and conditions including lighting, temperature, serving size, odours, and labelling of food samples to assure that errors due to psychological factors could be eliminated to the barest minimum, if not completely. 
Information in the scientific literature concerning texture profile and sensory attributes of meat products using gari as an ingredient in their formulations is very scanty. Gari is a cassava product that is relatively less expensive compared to other carbohydrate sources that can be used in meat formulations. It has characteristics that can be useful to meat texture and sensory improvement. In [8] reported that using 10\% hydrated gari in beef burgers reduced hardness significantly without any compromise on overall burger acceptability by consumers. The objective of this study was to evaluate the eating characteristics of wieners produced with gari as non-meat ingredient in partial replacement of beef. Specifically, the costs of production, instrumental texture profiling and consumer acceptability of wiener attributes were determined.

\section{Materials and Methods}

\section{Raw materials and wiener production}

Frozen beef trimmings and all spices were obtained from the Meat Laboratory of the Ohio State University. Gari was obtained from Ghana through the Berekum Market (Columbus, OH, USA), and used to replace beef $(\mathrm{w} / \mathrm{w})$ in four wiener treatments, comprising of control ( $0 \%$ gari with $20 \%$ water), and $3 \%$ gari formulated with $20 \%, 25 \%$ and $30 \%$ water respectively. The four treatments were respectively coded as 0T20, GT20, GT25 and GT30. The meat batter was produced using a Sydelmann chopper (Stuttgart, Germany) at a consistent temperature of $10.56^{\circ} \mathrm{C}$, stuffed into cellulose casings and hand-linked at $6 \mathrm{~cm}$ lengths. Wieners were cooked and smoked in an Enviro-Pack oven (Clackamas, OR, USA) to internal temperatures of $73.88^{\circ} \mathrm{C}$ after which they were chilled at $2^{\circ} \mathrm{C}$ overnight, vacuum packaged and stored at $-18^{\circ} \mathrm{C}$ for further analysis.

\section{Parameters measured}

Cost of production and cooking yield: The costs of producing wieners were calculated based on prevailing retail prices of beef trimmings, gari, cellulose casings and all spices used in their manufacture at Columbus, USA at the time of this study. Wieners were weighed before and after final cooking, and cooking yield was determined as a percentage of final weight to initial weight.

Texture profile: Wieners were either warmed in a water bath at $90^{\circ} \mathrm{C}$ to attain internal temperatures of $60^{\circ} \mathrm{C}$ or allowed to thaw at $2^{\circ} \mathrm{C}$ (cold) and cored to obtain cylindrical samples measuring $24 \mathrm{~mm}$ (height) by $16 \mathrm{~mm}$ (width) for texture profiling using Instron 5542 Texture Analyzer (Instron Co., Canton, MA, USA) as described by [8].

Sensory profile: A 9-point Hedonic scale was used to assess the sensory profile of the wieners at the OSU Sensory Laboratory. In all, 150 regular wiener consumers assessed the products based on overall acceptability, flavour, texture and odour desirability on a 9-point Hedonic scale, where 9 represented "like extremely" and 1 represented "dislike extremely." Wiener treatments were blind coded with random three-digit numbers and the order of serving samples to the consumers was randomized. Fifty consumers participated in each of three sessions of the evaluation process. The consumers comprised of students and staff of the Departments of Food Science and Technology and Animal Sciences, Columbus, $\mathrm{OH}, \mathrm{USA}$. The wieners were grilled (Star Grillmax Pro roller grill, Smithville, TN, USA) to internal temperatures of $60^{\circ} \mathrm{C}$ and cut into identical pieces of $3.0 \mathrm{~cm}$ lengths and served to the consumers. The core temperature of the wieners was monitored during cooking with a 12- channel thermocouple scanning thermometer (model 92000-00) (Eutech Instruments Pte Ltd., Singapore), and approval to use human subjects for the consumer evaluation was granted by the Office of Responsible Research Practices, The Ohio State University, USA.

Statistical analysis: All data generated from the study were subjected to one-way analysis of variance (ANOVA) in a completely randomized design. Significant differences between treatments were determined at $5 \%$ by Scheffé multiple comparison using [11] for Windows.

\section{Results and Discussion}

\section{Production cost, cooking yield and sensory profile}

Table 1: Production cost, Cooking yield and sensory profile of wieners ( \pm standard error)

\begin{tabular}{|c|c|c|c|c|c|}
\hline \multirow{2}{*}{ Parameter } & \multicolumn{5}{|c|}{ Wiener type } \\
\hline & $\mathbf{O T}^{20}$ & $\mathbf{G T}^{20}$ & $\mathrm{GT}^{25}$ & $\mathrm{GT}^{30}$ & P-value \\
\hline Cost $(\$ / \mathrm{kg})$ & 3.98 & 3.66 & 2.57 & 2.33 & \\
\hline Cooking yield (\%) & $88.17 \pm 0.01$ & $89.53 \pm 0.01$ & $91.43 \pm 0.02$ & $87.27 \pm 0.02$ & 0.63 \\
\hline Acceptability & $5.70^{\mathrm{a}} \pm 0.29$ & $6.38^{\mathrm{ab}} \pm 0.23$ & $6.88^{\mathrm{b}} \pm 0.19$ & $6.40^{\mathrm{ab}} \pm 0.25$ & 0.04 \\
\hline Texture & $5.90^{\mathrm{a}} \pm 0.33$ & $6.04^{\mathrm{ab}} \pm 0.28$ & $6.60^{\mathrm{b}} \pm 0.22$ & $6.44^{\mathrm{b}} \pm 0.24$ & 0.02 \\
\hline Flavour & $6.18 \pm 0.26$ & $6.14 \pm 0.23$ & $6.84 \pm 0.22$ & $6.44 \pm 0.26$ & 0.17 \\
\hline Odour & $6.02 \pm 0.20$ & $5.94 \pm 0.20$ & $6.38 \pm 0.21$ & $6.16 \pm 0.24$ & 0.25 \\
\hline
\end{tabular}

${ }^{\text {ab }}$ Means with different superscripts in same row are significantly different $(\mathrm{p}<0.05) .0 \mathrm{~T}^{20}=0 \%$ gari with $20 \%$ water; $\mathrm{GT}^{20}, \mathrm{GT}^{25}$ and $\mathrm{GT}^{30}=3 \%$ gari with $20 \%, 25 \%$ and $30 \%$ water respectively. Sensory attributes were scored for "like extremely = 9" to "dislike extremely $=1$.

Results obtained for the costs of producing wieners, cooking yield and sensory profile are reported in Table 1. Using gari with the different levels of water to substitute portions of the meat in the formulation of wieners seemed to favour cooking yields at the
$25 \%$ usage of water. However, the observed increases in cooking yields were not statistically significant $(p>0.05)$. Product yields ranged from $88.17 \%$ (control) to $91.43 \%$ when gari was used with $25 \%$ in wiener production. Wiener cooking yields were $89.53 \%$ 
when $20 \%$ water was used with $3 \%$ gari, however when water was increased to $30 \%$, the cooking yields reduced to $87.27 \%$. This probably was an indication that the maximum water needed in wieners formulated with $3 \%$ gari should not exceed $25 \%$ in order to obtain optimum cooking yields. Although the differences in cooking yields were not statistically different, meat processors may possibly benefit more, in terms of product yields if GT25 was adopted in wiener formulations because meat products are sold all over the world on weight basis. Sensory evaluation of the wieners revealed similar trends in the attributes evaluated (Table 1). Whereas overall product acceptability and texture attributes were influenced significantly $(\mathrm{p}<0.05)$ by the use of gari at the different levels of hydration, wiener flavour and odour were not significantly different $(p>0.05)$ from the control. The overall wiener acceptability score increased significantly $(\mathrm{p}<0.05)$ from 5.70 (control) to 6.88 when $3 \%$ gari was hydrated with $25 \%$ water. (Table 1 )

It was also observed that texture attribute score, as assessed by the consumers improved significantly $(p<0.05)$ at this level of hydration. Generally, all sensory attributes assessed by the consumers were higher at the $25 \%$ level of water usage in wiener formulations with gari.

\section{Texture profile}

Results of the TPA determinations are shown in Tables 2 and 3 for cold and warmed wieners respectively. With respect to the cold products, hardness, springiness, gumminess, chewiness and cohesiveness were all significantly different $(p<0.05)$ among treatments. The control product was significantly $(\mathrm{p}<0.05)$ harder, more gummy and chewy compared to all the gari-treated wieners. The mean hardness of the cold products reduced significantly $(\mathrm{p}<0.05)$ from 5.51(0T20) to 2.93 (GT30), springiness reduced from 9.29 (0T20) to 8.55 (GT30) while gumminess reduced from 30.44 (0T20) to 12.98 (GT30). Both chewiness and cohesiveness of the cold wieners also reduced significantly $(p<0.05)$ from 364.92 (0T20) to 155.55 (GT30) and 0.57 (control) to 0.43 (GT30) respectively, but adhesiveness was not significantly different ( $>0.05$ ) among treatments. (Table 2)

Table 2: Texture profile of cold wieners ( \pm standard error)

\begin{tabular}{|c|c|c|c|c|c|}
\hline \multirow{2}{*}{ Profile } & \multicolumn{5}{|c|}{ Wiener type } \\
\hline & $\mathbf{O T}^{20}$ & $\mathrm{GT}^{20}$ & $\mathrm{GT}^{25}$ & $\mathrm{GT}^{30}$ & P-value \\
\hline Hardness & $5.51^{\mathrm{b}} \pm 0.46$ & $3.61^{\mathrm{a}} \pm 0.19$ & $3.09^{\mathrm{a}} \pm 0.10$ & $2.93^{\mathrm{a}} \pm 0.16$ & 0.03 \\
\hline Springiness & $9.29^{b c} \pm 0.07$ & $8.96^{\mathrm{ab}} \pm 0.09$ & $8.84^{\mathrm{ab}} \pm 0.15$ & $8.55^{\mathrm{a}} \pm 0.22$ & 0.01 \\
\hline Gumminess & $30.44^{\mathrm{b}} \pm 2.24$ & $16.79^{\mathrm{a}} \pm 1.16$ & $13.99^{\mathrm{a}} \pm 0.76$ & $12.98^{\mathrm{a}} \pm 1.59$ & 0.02 \\
\hline Chewiness & $364.92^{\mathrm{b}} \pm 26.84$ & $201.34^{\mathrm{a}} \pm 13.93$ & $167.70^{\mathrm{a}} \pm 9.13$ & $155.68^{\mathrm{a}} \pm 19.11$ & 0.04 \\
\hline Cohesiveness & $0.57^{\mathrm{b}} \pm 0.02$ & $0.47^{\mathrm{ab}} \pm 0.02$ & $0.46^{\mathrm{a}} \pm 0.02$ & $0.43^{\mathrm{a}} \pm 0.04$ & 0.04 \\
\hline Adhesiveness (-10-4) & $9.2 \pm 0.0$ & $9.1 \pm 0.0$ & $10.1 \pm 0.0$ & $9.1 \pm 0.0$ & 0.26 \\
\hline
\end{tabular}

ab Means in same row with different superscripts are significantly different $(p<0.05)$; $0 \mathrm{~T}^{20}=0 \%$ gari with $20 \%$ water; GT ${ }^{20}, \mathrm{GT}^{25}$ and $\mathrm{GT}^{30}=3 \%$ gari with $20 \%, 25 \%$ and $30 \%$ water respectively.

A comparison of the texture profile of cold and warmed wieners revealed further reductions when wieners were warmed to attain internal temperatures of $60^{\circ} \mathrm{C}$ before texture profiling Table 3. Furthermore, hardness, gumminess and chewiness reduced significantly $(\mathrm{p}<0.05)$ in all the products with $3 \%$ gari and the varying levels of water compared to the control. The levels of water used with $3 \%$ gari aided in better moisture retention due to the carbohydrate component in gari compared to the control without gari. Springiness, adhesiveness and cohesiveness were however not significantly different $(\mathrm{p}<0.05)$ among treatments.
Hardness, springiness, gumminess, chewiness and adhesiveness of cold wieners reduced from 5.51(0T20) to 1.54 (GT30), 9.29 (0T20) to 7.84 (GT30), 30.44 (0T20) to 10.22 (GT30), 384.92 (0T20) to 102.09 (GT30), 9.20 (0T20) to 4.0 (GT30) respectively when wieners were warmed prior to TPA determinations. Warming the wieners probably resulted in melting the fat component and thus offering lesser resistance to rupture compared to the cold wieners. Thus, wieners will offer better eating quality when warmed before consumption compared to serving them cold. (Table 3)

Table 3: Texture profile of warm wieners ( \pm standard error)

\begin{tabular}{|c|c|c|c|c|c|}
\hline \multirow{2}{*}{ Profile } & \multicolumn{5}{|c|}{ Wiener type } \\
\hline & 0T20 & GT20 & GT25 & GT30 & P-value \\
\hline Hardness & $2.92^{\mathrm{b}} \pm 0.28$ & $1.91^{\mathrm{a}} \pm 0.07$ & $1.59^{\mathrm{a}} \pm 0.04$ & $1.54^{\mathrm{a}} \pm 0.12$ & 0.01 \\
\hline Springiness & $8.14 \pm 0.06$ & $8.01 \pm 0.07$ & $7.88 \pm 0.10$ & $7.84 \pm 0.07$ & 0.64 \\
\hline Gumminess & $19.56^{\mathrm{b}} \pm 1.69$ & $12.78^{\mathrm{a}} \pm 0.46$ & $10.44^{\mathrm{a}} \pm 0.29$ & $10.22^{\mathrm{a}} \pm 0.68$ & 0.03 \\
\hline Chewiness & $195.19^{\mathrm{b}} \pm 16.98$ & $127.62^{\mathrm{a}} \pm 4.57$ & $104.21^{\mathrm{a}} \pm 2.98$ & $102.09^{\mathrm{a}} \pm 6.83$ & 0.01 \\
\hline Cohesiveness & $0.69 \pm 0.01$ & $0.69 \pm 0.01$ & $0.68 \pm 0.01$ & $0.68 \pm 0.01$ & 0.85 \\
\hline Adhesiveness (-10-4) & $4.0 \pm 0.0$ & $2.2 \pm 0.0$ & $3.0 \pm 0.0$ & $2.3 \pm 0.0$ & 0.52 \\
\hline
\end{tabular}

${ }^{\mathrm{ab}}$ Means in same row with different superscripts are significantly different $(\mathrm{p}<0.05) ; 0 \mathrm{~T}^{20}=0 \%$ gari with $20 \%$ water; $\mathrm{GT}^{20}, \mathrm{GT}^{25}$ and $\mathrm{GT} \mathrm{T}^{30}=3 \%$ gari with $20 \%, 25 \%$ and $30 \%$ water respectively. 


\section{Conclusion and Recommendations}

Using gari in wieners had significant improvements in the sensory acceptability of the sausages. Though $3 \%$ gari in wiener formulations did not influence cooking yields, substantial savings were made on the costs of producing the wieners. Also, there were no adverse effects on flavour and odour of the wieners. More so, using gari in wieners formulations resulted in reduced hardness, gumminess and chewiness but had no influence on springiness, adhesiveness and cohesiveness. Furthermore, warming wieners resulted in reductions in their texture profiles. It was concluded that wieners could be produced with $3 \%$ gari and $25 \%$ water to obtain desirable texture and sensory profiles. We recommend that future studies should consider investigations on colour, storage ability and proximate composition of wieners produced with gari.

\section{Acknowledgement}

None.

\section{Conflict of Interest}

No conflict of Interest.

\section{References}

1. Bourne MC (2002) Principles of objective texture measurement. In: MCBourne (Ed.), Food texture and viscosity: Concept and measurement. San Diego, USA, pp. 107-188.
2. Kilcast D (2004) Force/deformation techniques for measuring texture. In: D Kilcast (Ed.), Texture in Food: Woodhead Publishing Ltd, Cambridge, UK, pp. 109-145.

3. Bourne MC (1978) Texture Profile Analysis. Food Technology 32: 62-72.

4. Bruna JM, Fernández M, Hierro EM, Ordóñez JA, de la Hoz L (2000) Combined use of pronase $\mathrm{E}$ and a fungal extract (Penicillium aurantiogriseum) to potentiate the sensory characteristics of dry fermented sausages. Meat Sci. 54(2): 135-145.

5. Mendoza E, García ML, Casas C, Selgas MD (2001) Inulin as fat substitute in low fat, dry fermented sausages. Meat Sci 57(4): 387-393.

6. de la Hoz F, Higuera AB, Di Fabio JL, Luna M, Naranjo AG, et al. (2004) Effectiveness of Haemophilus influenzae type $b$ vaccination against bacterial pneumonia in Colombia. Vaccine 23(1): 36-42.

7. Herrero AM1, Ordóñez JA, de Avila R, Herranz B, de la Hoz L, et al. (2007) Breaking strength of dry fermented sausages and their correlation with texture profile analysis (TPA) and physico-chemical characteristics. Meat Sci 77(3): 331-338.

8. Akwetey WY, Knipe CL (2012) Sensory attributes and texture profile of beef burgers with gari. Meat Science 92(4): 745-748.

9. IFT (Institute of Food Technologists) (1975) Minutes of Sensory evaluation division business meeting, 35th Annual Meeting, Chicago, USA.

10. Posté LM, Mackie DA, Butler G, Lamond E (1991) Laboratory Methods for Sensory Analysis of Food. Research Branch, Agriculture Canada Publication, USA.

11. SPSS (2006) (Statistical Package for Social Sciences) version 15.0.1 for Windows, Microsoft Inc, USA. 